\title{
Tarihsel Süreçte Dünya'da ve Türkiye'de Tarım Coğrafyası Alanındaki Çalışmalar
}

\author{
Studies on agricultural geography in the World and Turkey in the historical \\ process
}

Alparslan Aliağaoğlu*a

\begin{tabular}{l} 
MakaleBilgisi \\
\hline DOI: \\
10.33688/aucbd.593693 \\
\hline Makale Geçmişi: \\
Geliş: 24.06 .2019 \\
Kabul: 26.09.2019 \\
\hline Anahtar Kelimeler: \\
Coğrafya \\
Tarım \\
Tarım Coğrafyası \\
Türkiye Tarım Coğrafyası
\end{tabular}

\section{$\ddot{\partial} z$}

Tarım coğrafyast coğrafyanın temel konularından biridir. Ancak bu konudaki çalışmalar daha çok 20. yüzyılın başlarında yapılmıştır. Tarım coğrafyası konusundaki çalışmalar zaman içinde farklılaşmıştır. Bu farklılaşma her yerde aynı ölçüde olmamıştır. Bu çalışmanın arka planında Anglo-Sakson tarım coğrafyası olan bir resim içinde Türkiye tarım coğrafyasının doğası ve gelişimi üzerinde durulmaktadır. Çalışmada Türkiye'de coğrafya dergilerinde yayınlanan makaleleri dikkate alınmaktadır. Sonuç olarak görülmektedir ki Türkiye'de tarım coğrafyası yazınında konusal olarak çeşitlenme olmuştur. Yaklaşım konusunda Dünyadaki değişimlerden etkilenme söz konusu olmamıştır. Tarihsel süreçte Türk tarım coğrafyasının gelişiminde dört farklı evreden bahsedilebilir. Bunları; başlangıç yılları, sınırlı gelişim dönemi, çeşitlenmenin başlangıç yıllarl, çeşitlenmenin zirve yılları şeklinde sıralamak mümkündür.

\begin{tabular}{l}
\hline Article Info \\
\hline DOI: \\
10.33688/aucbd.593693 \\
\hline Article History: \\
Received: 24.06 .2019 \\
Accepted: 26.09 .2019 \\
\hline Keywords: \\
Geography \\
Agriculture \\
Agricultural Geography \\
Turkey Agricultural \\
Geography
\end{tabular}

\begin{abstract}
Agricultural geography is one of the basic subjects of geography. However, the studies on this subject were mostly made in the early 20th century. Studies on agricultural geography have differentiated over time. This differentiation has not been the same as everywhere. In this study, standings in the background of a picture with the Anglo-Saxon farming, the nature and development of Turkey's agricultural geography are studied. Geography articles published in geographical periodical in Turkey are taken into account in the study. As a result, it is seen that, in time, Turkey has been diversification in agricultural geography thematically. Four different phases can be mentioned in the development of Turkish agricultural geography. These are start years, limited development period, beginning years of diversification, peak years of diversification.
\end{abstract}

\footnotetext{
*Sorumlu Yazar/Corresponding Author: Alpaslan Aliağaoğlu, alpaslan38ster@ gmail.com

a'Balıkesir Üniversitesi, Fen-Edebiyat Fakültesi, Coğrafya Bölümü, Balıkesir, Türkiye, http://orcid.org/0000-0002-6198-3878
} 


\section{Giriș}

Coğrafya, insanı yaşadığı mekânla birlikte ele alarak faaliyetlerini mekânla ilişkili biçimde incelemektedir. Tarım bu faaliyetler arasında en eski olanıdır. İnsanoğlu tarımsal faaliyetleri ile mekâna bilerek müdahale etmiş ve farklı bir görünüm kazandırmıştır. Tarım coğrafyası tarımsal coğrafi görünümün mekânsal yönleriyle ilgilidir. Tarımsal uğraşı fiziki ve beşeri birtakım etkenlerle şekillenmekte ve bu şekil zamana ve mekâna göre değişmektedir. Coğrafya dinamik bir yapıya sahiptir. Geçmişten günümüze zaman içinde değişik coğrafi bilgi üretimi söz konusu olmuştur. Bu özellik doğal olarak tarım coğrafyasının yapısında da vardır. Coğrafya gelişme tarihi içinde farklı bakış açılarının hâkimiyeti söz konusu olmuştur. Bu bakış açıları birbirini takip eden bir seyir içinde olduğu gibi üst üste geçmeler şeklinde de yaşanmıştır. 1950 ve 1970 li yıllar coğrafya ve diğer bilimler için dönüm noktası olmuştur. Özellikle 1970 li yıllar coğrafyada çoklu bakış açısının yaşanmaya başlandığı yıllardır. Bu durum tarım coğrafyasını da etkilemiş, ancak çoklu bakış açısı tüm dünyada aynı yoğunlukta yaşanmamıştır.

"Bir disiplinin üyeleri için zaman zaman geriye bakarak kat edilen yolları ve aşılan merhaleleri mukayeseli bir şekilde gözden geçirmek" (Erinç 1973: 1), "disiplinin gösterdiği performans1 analiz etmek ve bilim yaşamındaki yerini ve katkılarını ortaya koymak kendi topluluklarının ve disiplinlerinin değerlendirmesini yapmak, neredeyse bir zorunluluktur" (Özgür ve Yavan, 2013: 15). $\mathrm{Bu}$ açıdan yakın dönemde farklı çalışmalar yapılmıştır: Akyol (1943a), (1943b), (1943c), Erinç (1973), Erinç (1997), Tümertekin (1971), Tümertekin (1998), Koçman (1999), Kayan (2000), Özgür ve Yavan (2013), Gümüşçü ve Karakaş Özür'ün (2016) çalışmaları bunlar arasındadır. "Bir Disiplinin İç Dünyası: Modern Türk Coğrafyası Üzerine Söyleşiler" (Bekaroğlu ve Özdemir, 2014) adlı eser, bu konuda yapılan başka bir çalışmadır. Eserde coğrafyanın alt dallarının doğası, gelişimi, bugünkü durumu hakkında bilgi verilmiş, ancak tarım coğrafyasına yer verilmemiştir. Hiç kuşkusuz Doğanay ve Coşkun (2012) bu konuda tarım coğrafyasının iç tarihini vermişlerdir. Bu çalışma iç ve dış tarihi gelişimi vermesi, karşılaştırma yapabilmeyi sağlaması açısından önemlidir. Çalışma aşağıda belirlenen soruların cevabını anlamaya yöneliktir:

a) Modern anlamda tarım coğrafyasının konusu, kapsamı, amacı ve araştırma objesi nedir?

b) Tarım coğrafyasının geçmişi, kökeni neresidir? Nerede ortaya çıkmıştır?

c) Tarım coğrafyasında kullanılan yaklaşımlar nelerdir?

d) Türkiye'de tarım coğrafyası nasıl bir gelişim çizgisi sergilemiştir? Öncüleri kimlerdir?

e) Tarım coğrafyasında kullanılan yeni yaklaşımların hangileri Türkiye'de kullanılmaktadır?

f) Tarım coğrafyası Türkiye'de hangi yönde gelişmeli ve hangi konulara yer verilmelidir? 
Çalışmada kısa bir giriş kısmından sonra yöntem ve sınırlılıklar verilmektedir. Tarım ve tarım coğrafyasının özellikleri ile dünyada tarım coğrafyasında kullanılan başlıca konular ve yaklaşımlar çalışmanın arka planını veya kavramsal çerçevesini oluşturmaktadır. Türkiye tarım coğrafyasının doğası ve gelişimi başka bir bölümün konusudur. Çalışma sonuç ve öneriler bölümü ile son bulmaktadır. $\mathrm{Bu}$ bölümde çalışmanın problemi tekrar ifade edildikten sonra, araştırma soruları temelinde kısa genellemelere yer verilmektedir. Tarım coğrafyasının Türkiye'de hangi yönde gelişmesi gerektiği üzerinde durulmaktadır.

\section{Materyal ve Yöntem}

Çalışma esas itibarıyla literatür değerlendirmesidir. Öncelikle Türkiye'de yayınlanan coğrafya dergilerindeki tarım coğrafyası makaleleri ele alınmaktadır. Kısmen kitaplara yer verilmektedir. Çalışmada pozitif-normatif yaklaşım kullanılmaktadır. Pozitif yaklaşımda Türkiye'deki mevcut tarım coğrafyası çalışmaları değerlendirilirken, normatif yaklaşımda Anglo-Sakson coğrafyasında tarım coğrafyasının gelişimi ölçek olarak kullanılmakta ve yazar öznel bakış açısıyla Türk tarım coğrafyasının geçirdiği evreleri ortaya koymaktadır. Türk tarım coğrafyasında yapılan makale ve kitaplar değerlendirilirken, Yavan ve Özgür'ün (2013), Türk Coğrafyasının tarihsel gelişim aşamaları kullanılmaktadır. $\mathrm{Bu}$ aşamalar dört evreden oluşmaktadır. Bunları; Kuruluş ve Kurumsallaşma Evresi: Modern Türk Coğrafyasının Ortaya Çıkışı (1915-1949), Sınırlı Gelişme Evresi: Atılım ve Duraklama (1950-1980), Türk Coğrafyasının En Zor Yılları: Bilimsel Topluluktan Uzaklaşma (1981-2000) ve Yeniden Canlanma Evresi: Yeni Arayışlar ve Uyum Çabaları (2001 sonrası) şeklinde sıralamak mümkündür. Bu çalışmada coğrafyanın gelişim aşamalarının adlarından çok tarihi dönemlendirme dikkate alınmaktadır. Çalışmada hayvancılık da tarım faaliyeti içinde değerlendirilmektedir. Çünkü insan kontrolünde tarımsal arazi üzerinde yapılması, Türkiye'de tarımsal işletmelerin çoğunda (\%70, Tümertekin ve Özgüç, 2016: 150) tarımsal faaliyete ek bir etkinlik olması nedeniyle hayvancılık tarımsal faaliyet içine dâhil edilmiştir. Rumney'in (2005) Agricultural Bibliyografyası tarımın Anglo-Sakson ülkelerindeki çalışma konuları hakkında bilgi vermekte ve hayvancılık faaliyetleri de işlenmektedir.

Dünyada tarım coğrafyası konusu işlenirken, Alman ve Fransız coğrafyacılarının tarım coğrafyasına yaptıkları katkılar, kaynaklara erişim sorunu ve dil engeli nedeniyle bütünüyle değerlendirilmemektedir.

\section{Kavramsal Çerçeve}

\subsection{Dünyada tarım coğrafyası, başlıca yaklaşımlar}

Tarım medeniyetin ilk aşaması, bir ekonomik faaliyet veya girişim ve yaşam biçimidir. Ekonomik faaliyetler arasında önemli bir konumda olan tarım, insan ihtiyaçlarını karşılamak maksadıyla, farklı sosyal, ekonomik ve fiziki çevrelerde amaçlı olarak yapılan bitkisel üretim ve hayvan yetiştiriciliğidir. Bilinen bu faaliyetler yanında, pazar bahçıvanlığı, ağaçsı plantasyon ürünlerinin ekimi, hasat edilmesini, ot ve baklagiller ekimi, çiftlik havuzlarında balık yetiştiriciliği ve mink çiftliklerinde mink yetiştiriciliğini de kapsar (Thoman, 1962). Amaçlı olarak yapılması nedeniyle avcılık ve toplayıcılıktan ayrılır. Ayrıca İskandinav çiftçileri, tarımın yanında ormancılık faaliyetleri 
ile uğraşırken, Asya kıtasında kıyı köyleri tarım ve balıkçılığı birlikte yapmalarına rağmen ormancılık ve balıkçlık tarımsal faaliyet olarak düşünülmemektedir (Grigg, 1995; Symons, 1967).

Tarım çok sayıda işleve sahiptir. Tarım bir meslektir. İnsanlar yemek, giyinmek ihtiyacını tarımdan karşılarlar. Bu yönüyle sanayiye ham madde sağlar. Hayvanların da temel besin kaynağıdır. Farklı ölçeklerde birey veya devletler için kazanç kapısıdır. Ekonomiyi olumlu yönde etkiler. Çevrenin güzelleşmesini sağlaması da başka bir yönüdür. Doğal çevreye bağımlı olması, çeşitlilik ve karmaşa da belirtilmesi gereken diğer özelliklerdir. Yine tarımsal faaliyete katılan çiftçi sayısı çok, fakat tarımsal ürünlerin pazarlanması az sayıda insan tarafından yerine getirildiğinden, fiyat belirleme de çiftçi nüfusun etkisi az olmaktadır.

Tarımsal faaliyetlerin sınırlarını kabaca iklim ve hava koşulları belirler. Bu sınırlar dâhilinde topografyanın farklı bir etkisi vardır. Toprak koşulları da bu başlıkta ele alınabilir. Bu limitler dâhilinde insanoğlunun çevreye müdahalesi, onun gelişme aşamasına bağlıdır. Bilim ve teknolojiyi kullanma, ekonomik ve sosyal kurumlar ve örgütlenmeler bu bağlamda ön plana çıkarlar. Irk, etnik temel, dinin etkisi de dikkate alınmalıdır. Son olarak ekonomik (fiyat ve maliyet) ve siyasi koşullar da tarımsal faaliyeti etkilemektedir (Symons, 1967).

Tarım ile farklı bilimler ilgilenmektedir. "Geniş anlamda tarım, teknik bir bilimler topluluğu olup, hayvansal ve bitkisel ürünler elde etmek üzere, biyolojik, sosyal ve ekonomik çevrede sürdürülen ekonomik etkinliklerin bütünüdür" (Doğanay ve Coşkun, 2012: 5). Tarım, tarımsal ekonomi ve coğrafya bunlar arasındadır. Türkçe Bilim Terimleri Sözlüğünde tarım; "Toprağı işleyerek yayarlı ürünler elde etmeye dayanan, geniş anlamıyla hayvancılığı da kapsayan yaşamsal etkinliktir" (Türkçe Bilim Terimleri Sözlüğü, 2011: 1101) şeklinde tanımlanmaktadır. Emiroğlu vd. (2006: 849), ekonomi sözlüğünde, tarımı "bitki ve hayvan yetiştirilmesi ve avlanma yoluyla yapılan üretimi kapsayan bir etkinlik" olarak ifade etmektedirler. Tarım geniş anlamıyla, "ekilip dikilen topraklardan faydalanmadır. Tarım bitkilerinin yetiştirilmesi, doğal çayır ve otlaklardan faydalanma, hayvan yetiştiriciliği faaliyetidir. "(İzbırak, 1986: 301). Tarım coğrafyası, "yeryüzündeki tarımsal faaliyetteki mekânsal değişimleri tanımlamak ve tarımsal faaliyetler ile mekansal kullanım ilişkilerini sebep ve sonuçlarıyla açıklamaktır (Sertkaya Doğan, 2018: 199). Kuşkusuz hayvancılık faaliyetlerini tarımsal faaliyete dâhil etmeyen bilim insanları da vardır. Özçağlar (2003), konuyu hammaddeler coğrafyası içinde ele almaktadır. Tarım, "gerekli, yararlı bitkiler yetiştirmek amacıyla toprak üzerinde yapılan çalışmaların bütünü" (Özçağlar, 2003: 128) olarak tanımlanmaktadır. Bulut da (2006) aynı görüştedir: Tarım, "topraktan ürün almak amacıyla toprağın işlenmesi, tohumun ekilerek veya fidan dikilerek zirai bitki yetiştirilmesi ve olgunlaşan ürünün hasat edilmesi" (Bulut, 2006: 1) faaliyetidir. Bize göre tarım, tarımsal arazi üzerinde insan kontrolünde yapılan hayvancılık ve bitkisel üretim faaliyetlerini kapsayan ekonomik etkinliktir. Tarım coğrafyası tarımsal faaliyetler sonucu şekillenen mekânsal farklılıklarla ilgilidir. Morgan ve Munton'un da (1971) ifade ettiği şekilde tarım, bitkisel ürerim ve hayvancılık faaliyetlerini kapsayan tarım kuruluşlarının mekânsal yönüyle ilgilidir.

Tarım coğrafyası, coğrafyanın gelişme tarihinde ortaya çıkan farklı paradigmalardan etkilenmiştir. Bu anlamda başlangıçta sistematik ve bölgesel bakış açılarıyla daha çok tümevarımcı ve 
çevreci determinist yaklaşımla çalışmalar yapılmıştır. Emtiayı dikkate alan konusal bakış açısı daha çok Birleşik Krallıkta yapılmıştır (James ve Jones, 1988) . Bölgesel bakış açısı Kıta Avrupası'nda yapılmıştır. Bazı ürünlerin (çay, pamuk vb.) dağılışı tasvir edilmiş ve açıklanmıştır. Bu konuda yapılan çalışmalar daha çok Avrupalıların sömürgelerinin tarımsal potansiyelini ortaya koyacak tarzdadır. Laderlin ve Galloıs 1918 yılında dünyadaki pamuk tarım sahalarını ele almışlardır. Bu yöndeki çalışmalar daha çok fiziki çevre-tarım arasındaki ilişkileri ortaya koymaktadır (aktaran Tümertekin, 1984).

ABD'de tarım coğrafyası çalışmaları 1910-1920 yılları arasında başladı. Ülkede arazi kullanışı, toprak-eğim koşulları ve tarımsal arazinin ayrıntılı olarak haritalanması üzerinde çalışmalar yapılmıştır. Jones ve Sauer tarafindan 1915 yılında yayınlanan , "Arazi çalışmalarının sınırları" adlı çalışma, ABD'de konunun daha çok tarımsal arazi haritalanması şeklinde başladığını göstermektedir. 1925 y1lında Jones ve Finch ve Whittlesey'de benzer şekilde çalışma yapanlar arasındadır. O.E. Baker zamanının en bilinen tarım coğrafyacısıydı. 1923 yılında yaptığı, "Büyük Ovalarda Tarım" adlı eseri sonraki yıllar için uygulamalı coğrafyanın erken eserlerindendir. 1917 yılında dünya tarım atlası adlı eseri yazdı. Tarım coğrafyası yanında nüfus uzmanı da olan Oliver E. Baker (Visher ve Hu, 1950), 1926-1933 yılları arasında Kuzey Amerika tarım bölgeleri tespiti konusunda çok sayıda (11 adet) yayın yaptı. Bu yayınlar 1925 yılında kurulan Ekonomik Coğrafya dergisinde yayınlandı. Whittlesey'in (1936) "Dünya Tarım Bölgeleri" adlı çalışması da önemli bir eserdir. Hiç kuşkusuz Whittlesey bu konuda ilk ve tek değildir. Nitekim Grigg'in (1969) tespitlerine göre, dünya tarım bölgelerinin tespitin yönelik çok sayıda (12 adet) çalışma yapılmıştır. 1974 yılında yazılan başka bir eserde Dünya Tarımsal Sistemleri ele alınmaktadır. Grigg tarafindan yazılan eser, Dünya Tarım Bölgelerinin ayrıntılı açıklanmasıyla ilgilidir. ABD'de TVA projesinde arazi kullanımını belirlemek maksadıyla da çalışmalar yapılmıştı (aktaran Gregor, 1970: 17).

Tarım coğrafyası kuşkusuz başka eserlerde (ekonomik coğrafya) de bölümler halinde verilmektedir (Bengtson ve Van Royen 1956, Jones ve Darkenwald, 1965). Ancak tarım coğrafyası başlıklı ilk eserler Fransızlar tarafından yazılmıştır. George'nin ilki 1946, ikincisi 1962 yılında yayınlanan "Dünya Tarım Coğrafyası" bunlardan biridir (aktaran Tümertekin, 1984). Klages (ABD, 1942) bu konuda ilklerden sayılır. Yazar konuyu ekolojik bakış açısıyla ele almaktadır. Ancak tarımsal faaliyeti etkileyen ekolojik koşullar ve tarımsal ürünler yanında, tarımsal üretimin geçmişi, tarımsal gelişme ve nüfus arasındaki ilişki ve tarımsal üretimin sosyal çevresi ile ilgili bilgiler de verilmektedir. Eser, şekilsel olarak Türkiye'de yapılan tarım coğrafyası ders kitaplarıyla benzerlik göstermektedir. Otremba'nın (Almanya, 1953) eseri daha çok tarım coğrafyasının hangi yönde gelişmesi gerektiğiyle ilgilidir (aktaran Tümertekin 1984). Sauer 1952 yılında kültüre alınmış bitki ve hayvanların yayılımı konusunda önemli bir eser yazmıştır. Anderson (1970), Morgan ve Munton (1971), Tarrant (1974), Tarım Coğrafyası başlığı taşıyan diğer eserleri vermişlerdir. 1950-1960'lı yıllarda coğrafya ve dolayısıyla tarım coğrafyasında yaklaşım bakımından önemli değişiklikler yaşanmıştır.

Coğrafyada sayısal devrim yaşanmış, tarımsal faaliyetler 1950'li ve 1960'lı yıllarda ekonomik bakış açısıyla ele alınır olmuştur. Daha çok ekonomik deterministik model olarak tanımlanan modelde (1985), piyasa koşulları, üretim ve ulaşım maliyetleri tarımsal kullanışı belirlemektedir. Coğrafyacılar Von Thünen'in 1826 yılında yazılan 1966 yılında İngilizceye çevrilen İzole Devlet Modelini yeniden 
keşfetmiş̧lerdir. Başka bir anlatımla coğrafyacılar tarımsal faaliyetin ölçülebilir mekânsal yönleri ve kurallarıyla ilgili olmuşlardır. Öyle ki Tarrant (1974) Tarım Coğrafyası başlıklı eserinin giriş kısmında, tarımı, ekonomik kuvvetlerin sıkı kontrolünde olan bir yaşama biçimi olarak görmektedir. Kitabın giriş bölümünde tarımsal lokasyon teorisi anlatılmaktadır. Diğer başlıklar; tarımsal veri kaynakları, bölgeselleşme ve sinıflandırma, bölgeselleşmede problem ve seçenekler, tarım coğrafyasında açıklama ve ilişkiler, tarımsal pazarlama, tarımsal arazide rekabet şeklinde siralanmaktadir.

1970 ve 1980'li yıllarda tarım coğrafyasının ele aldığı konularda önemli değişiklikler olmuştur. $\mathrm{Bu}$ durum bir yandan beşeri coğrafyada yaşanan paradigma değişimleri, bilimin çok disiplinli olma karakteri ve dünya ölçüsünde yaşanan ekonomik değişimlerle ilgili olmuştur. Böylece, daha çok gelişmiş olan ülkelerde olmak üzere, tarım coğrafyasında farklı konular ele alınmaya başlanmıştır. Bunlar endüstriyel tarım sisteminin özellikleri veya tarımda küreselleşme, tarımsal arazi kayıpları, devletin tarıma müdahalesi ve yarı zamanlı çiftçilik şeklinde sıralanabilir (Rabinson, 2004). Tarım coğrafyası konularının kırsal ekonomide ele alınır oluşu başka bir durumdur. Bu durum gelişmiş ülkelerde, tarım ekonomisinin genel ekonomi içindeki payının azalmış olması ile ilgilidir.

Tarım coğrafyası çalışmalarında 1970'li yıllarda davranışsal yaklaşım ön plana çıkmıştır. Sosyo-ekonomik model olarak da ifade edilen yaklaşımda çiftçi nüfusun değerleri, amaçları, motivasyonları ve tavırlarının tarımsal faaliyetlerde karar vermeyi etkilediği ifade edilmektedir. Wolpert'e ait olan "Mekânsal Ortamda Karar Verme Süreci" adlı makale, "Bahsi geçen zamanda büyük oranda kabul gören kural koyucu teoriye alternatif olarak davranışsal bakış açısını önermiş ve davranışsal coğrafyanın doğuşuna ön ayak olmuştur". Wolpert'e göre; "İsveç'in orta kesiminde faaliyetlerini yürüten çiftçilerin çalışma verimi için geliştirdikleri akıl teorilerinin gevşetilmesi gereklidir. Çiftçi nüfusunun gruplar halinde ele alınması ile beklenen düzeyde kâr sağlanması ve istenilen hedefe ulaşılması zor olmaktadır. En doğru bilgi ve önceden kestirilmesi zor olan değişimler, iletişim ve bilgi düzeylerindeki yeterlilik ile sağlanabilir. "Çiftçilerin vermiş olduğu kararlar onların değer yargılarını ifade etmektedir" (aktaran Singh ve Dhillon, 1984) .

Davranışsal coğrafya konusunda İngiltere de İlbery ön plana çıkmaktadır. Onun Tarım Coğrafyası (1985) başlıklı kitabı da vardır. Bu kitapta konuya sosyal ve ekonomik bakış açısı getirmektedir. İllbery (1983), Batı Midlands'de şerbetçiotu yetiştiricilerinin amaç ve değerlerini ortaya koyduğu çalışmayı, davranışsal tarım coğrafyası yaklaşımı ile ele almaktadır. .

1980'li yıllardan günümüze doğru etkili olan radikal model başka bir bakış açısı getirmektedir. Modele göre, yüksek teknoloji ve büyük tarımsal tüccarlar tarımsal ilerlemenin ibareleri değildir. Post endüstriyel toplumlarda tarımın geleceği, büyük tarım tüccarlarına rağmen, ekonomik olarak ayakta kalmış tarımsal toplumlara bağlı kalacaktır (Illbery 1985). Başka anlatımla tarımsal ekonomi devletin ekonomik hayata müdahalesi anlamına gelmektedir. Yaklaşım Ricardo ve Marx'ın değer, yeniden üretim ve dağıtım fikirlerine dayanmaktadır. Bu konuda Marsden vd. 1996, dört farklı çalışma alanı belirlemektedirler. Bunları; tarımda az gelişmişlik süreci, eşitsiz tarımsal gelişmeyi anlamada tarihi ve yerel olan özgünlüğü bir araya getirme ihtiyac1, aile çiftçiliğinin kapitalist sistem içinde analiz 
edilmesi ve son olarak devletin her seviyedeki aşamaya bütünleşme hareketi şeklinde sıralamak mümkündür. Bu konuda ilk eser Kuatsky tarafından 1890'lı yıllarda ele alınan "Tarım Sorunu" adlı eserdir (Aktaran Marsden, 1996: 363). Eserde 20. yüzyılın ikinci çeyreğinde yaşanan büyük tarımsal depresyon ele alınmaktadır.

1990'ların başında, dikkatler, iki açıdan çiftlik kavramının ötesine çevrilmişti. Birincisi, tarımsal gıda sistemindeki sermaye birikiminin daha geniş bir organizasyonuna bakmak gerekir. Bunun için de tarımsal teknoloji ürünleri ve hizmetleri; gıda işleme; perakende satış olarak adlandırılan üç endüstriyel faaliyet grubu ile gıda yetiştiriciliği arasındaki sosyal, ekonomik ve teknolojik bağlara odaklanmak. İkincisi, bu sistemin düzenleyici yapılarına bakmak için, ulusal ve ulus üstü devlet kurumlarının tarım piyasalarını desteklediği politik ve politika süreçlerine odaklanmak. Bu genişletilmiş tarımsal gıda üretim ve düzenleme parametrelerini anlama çabaları, meta zincirleri ve gıda rejimleri gibi çeşitli yeni kavramların geliştirilmesine yol açmıştır (Robinson, 2004).

Anglo-Sakson ülkelerinden tarım coğrafyası çalışmalarında çeşitlilik görülmektedir (Çizelge 1). Bir bütün olarak bakıldığında genel metin, makale ve tezler ön plana çıkmaktadır. Tarımsal arazi çalışmalarında Birleşik Krallık ön plana çıkmaktadır. Yapılan çalışmaların çokluğu bir başka özelliktir. Nitekim Birleşik Krallık toplam 475 adet tarım coğrafyası ile ilgili çalışma ile ön planda iken ABD'de toplam 255 yayın yapılmıştır. Bu durum İngiliz Milletler Topluluğunun ekonomik sistemini geliştirmek için gıda ve hammadde kaynaklarını öğrenme çabasının bir sonucudur. ABD'de çeşitli iklim alanlarının varlığına bağlı olarak artan tarım coğrafyası çalışmaları, Kanada'da çeşitli nedenlerle azalmaktadır. Bu durum daha çok iklim nedeniyle tarıma uygun olmayan alanların çokluğu ile ilgilidir. Mandıracılık, tarımsal pazarlama ve dağııım, ulaşım ve makineleşme çalışmaları Türkiye'de yapılan çalışmalardan farklılık arz etmektedir.

Çizelge 1. Anglo-Sakson ülkelerinde tarım coğrafyası çalışma konuları

\begin{tabular}{|c|c|c|c|c|}
\hline \multirow[t]{2}{*}{ Konular } & \multicolumn{3}{|c|}{ Ülkeler } & \multirow{2}{*}{ Toplam } \\
\hline & $\mathrm{ABD}$ & Kanada & Birleşik Krallık & \\
\hline Atlas ve grafik, sunumlar & 5 & 1 & 17 & 23 \\
\hline Genel metin, makale ve tezler & 75 & 35 & 170 & 280 \\
\hline Tarımsal ürün ve ürün kalıpları & 65 & 7 & 51 & 123 \\
\hline Hayvancılik & 23 & 4 & 22 & 49 \\
\hline Mandıracılık & 13 & 3 & 6 & 22 \\
\hline Tarımsal arazi & 26 & 15 & 100 & 141 \\
\hline $\begin{array}{l}\text { Tarımsal işgücü ve sosyal } \\
\text { konular }\end{array}$ & 11 & 6 & 29 & 46 \\
\hline $\begin{array}{l}\text { Çevresel konular ve çevresel } \\
\text { koruma }\end{array}$ & 18 & 7 & 54 & 79 \\
\hline Sulama & 4 & - & 1 & 5 \\
\hline Su kültürü & 1 & - & 3 & 4 \\
\hline Tarımsal pazarlama ve dağıtım & 10 & 4 & 13 & 27 \\
\hline Ulaşım ve makineleşme & 3 & 1 & 4 & 8 \\
\hline Tarımsal işgücü çalışmaları & 1 & 2 & 5 & 8 \\
\hline TOPLAM & 255 & 85 & 475 & 815 \\
\hline
\end{tabular}

Kaynak: Rumney, 2005 


\section{Bulgular: Türkiye'de Tarım Coğrafyası}

Kuruluş ve Kurumsallaşma Evresinde Türkiye'de 50 coğrafya makalesi yayınlanmış, bunlardan sadece dördü tarım coğrafyasıyla ilgili olmuştur (Çizelge 1). Bu duruma bakarak, bu evreyi tarım coğrafyasında başlangıç dönemi olarak nitelemek yanlış olmayacaktır. Tarımsal üretim konulu çalışmalar sayıca en fazla olandır (2 adet). Dönemde, kitap bazında yapılan çalışmaların sayısı daha fazladır. Türkiye'de Cumhuriyet dönemi öncesi ve Cumhuriyet döneminde yapılan çalışmalar Doğanay ve Coşkun (2012) tarafından yazılan Tarım Coğrafyası adlı eserde ayrıntılı olarak ele alınmaktadır. Bu esere göre, Cumhuriyet Dönemi öncesinde Binbaşı Hüseyin ilk eseri veren kişidir. Eser Osmanlı Ülkeleri Ziraat Coğrafyası başlığına sahiptir (Doğanay ve Coşkun, 2012). Yine Osmanlı Coğrafya-yı İktisadisi, Faik Sabri tarafından I. Dünya Savaşından önce yayınlanmıştır (Tümertekin, 1971).

Cumhuriyet döneminde Ali Macit Arda'nın Beşeri Coğrafyasından (1936) sonra, Rustow 1939 yılında İktisadi Coğrafya adlı eseri yayınlanmıştır. Eser bütünüyle tarımsal ürünlerin özellik ve dağılışını verirken, hayvancılık ile ilgili bilgilere de yer verilmektedir. Daha doğrusu eser nebatlar ve faydalı hayvanlar şeklinde iki ana başlık altında incelenmektedir. Tanoğlu 1942 yılında Ziraat Hayatı adlı eseri yazmıştır. Eser tarımın tarihi ve orta kuşak memleketlerinde ziraat hayatı ile ilgilidir. Ziraat hayatı tarımın tarihi gelişimini vermektedir ve Alman ekolunun (Ritter'in) etkisi görülmektedir.

Türkiye'de 1950-1980 arasındaki dönemde yayınlanan tarım coğrafyası makale sayısı 16 adet olmuştur. Bunlara Erinç ve Tunçdilek (1952) tarafından yayınlanan "The Agricultural Regions of Turkey" ve Tümertekin'in (1964), "Changing Picture of Famale Participation in Turkish Agriculture" adlı yabancı yayınları da eklenmelidir. Tarım coğrafyasının bu dönemini sınırlı gelişim yılları olarak nitelemek mümkündür. Tarımsal ürünler (6 adet) diğer konulardan sonra gelmektedir. Diğer çalışmaların (7 adet) varlığına bağlı olarak konusal çeşitlenme sınırlı ölçüde yaşanmaya başlanmıştır. $\mathrm{Bu}$ dönemde, Türkiye'de emek göçünün şehirleşmesi yaşanmıştır. Bu durum tarımda makineleşme başta olmak üzere çeşitli nedenlerden kaynaklanmıştır. Şehirsel ortamda gecekondulaşma ve buna bağlı olarak şehirsel alanlar büyümüş ve tarım arazileri amaç dışı kullanılmaya başlamıştır. $\mathrm{Bu}$ durumları ortaya koyan makaleler ancak bir dönem sonra yazılmıştır. Türkoğlu 1958 yılında İktisadi Coğrafya Dersleri, Birinci Kitap Gıda Maddeleri başlıklı kitabı yazmıştır. Aynı eser 1979 yılında tekrar basılmıştır. Tümertekin'in Kurak Bölgelerde Ziraat Hayatı (1957), Beşeri ve İktisadi Coğrafya Dersleri (1961) ve İktisadi Coğrafya (1972) kitapları basılmıştır. Beşeri ve İktisadi Coğrafya dersleri başlıklı kitabında, tarım coğrafyası son bölümü oluşturmaktadır. Nüfus, meskenler, yerleşmeler ve siyasi coğrafya diğer bölümlerdir. İşlenen konular sonradan yayınlanan İktisadi coğrafya kitabının da temel konuları olmuştur. Tanoğlu'nun Ziraat Hayat adlı eserinin ikinci baskısı yapılırken (1968), on bir yıl sonra yayınlanan başka bir eser Göney'e aittir: Türkiye Ziraatının Coğrafi Esasları 1. Takip eden dönemlerde yazılan makale sayısında önemli artışlar yaşanmıştır. Ancak bu artışlar yaklaşımlarda değişim şeklinde olmamıştır. 
Çizelge 2. Türkiye'de coğrafya dergilerinde yayınlanan tarım coğrafyası konulu makale sayıları

\begin{tabular}{|c|c|c|c|c|c|c|c|c|}
\hline \multirow[t]{3}{*}{ Dergiler } & \multicolumn{8}{|c|}{ Dönemler } \\
\hline & \multicolumn{2}{|c|}{$1915-1949$} & \multicolumn{2}{|c|}{$1950-1980$} & \multicolumn{2}{|c|}{$1981-2000$} & \multicolumn{2}{|c|}{$2001+$} \\
\hline & $\mathrm{T}$ & Tarım & $\mathrm{T}$ & Tarım & $\mathrm{T}$ & Tarım & $\mathrm{T}$ & Tarım \\
\hline Türk Coğrafya Dergisi & 50 & 4 & 96 & 14 & 224 & 12 & 237 & 13 \\
\hline Coğrafya Dergisi & & & & & 90 & 4 & 137 & 19 \\
\hline Doğu Coğ. Dergisi & & & & & 71 & 3 & 476 & 45 \\
\hline Ege Coğ. Dergisi & & & & & 100 & 2 & 113 & \\
\hline $\begin{array}{l}\text { Coğrafi Araştırmalar } \\
\text { TÜCAUM } \\
\text { Coğrafi Bilimler Dergisi }\end{array}$ & & & 61 & 2 & 141 & 9 & 171 & 10 \\
\hline Atatürk Kültür & & & & & 59 & 5 & & \\
\hline $\begin{array}{l}\text { İst. Ünv. Den. Bil. Coğ } \\
\text { Ens. Dergisi }\end{array}$ & & & & & 167 & 6 & & \\
\hline Marmara Coğrafya Dergisi & & & & & 37 & 2 & 526 & 20 \\
\hline Toplam & 50 & 4 & 157 & 16 & 722 & 43 & 1660 & 107 \\
\hline
\end{tabular}

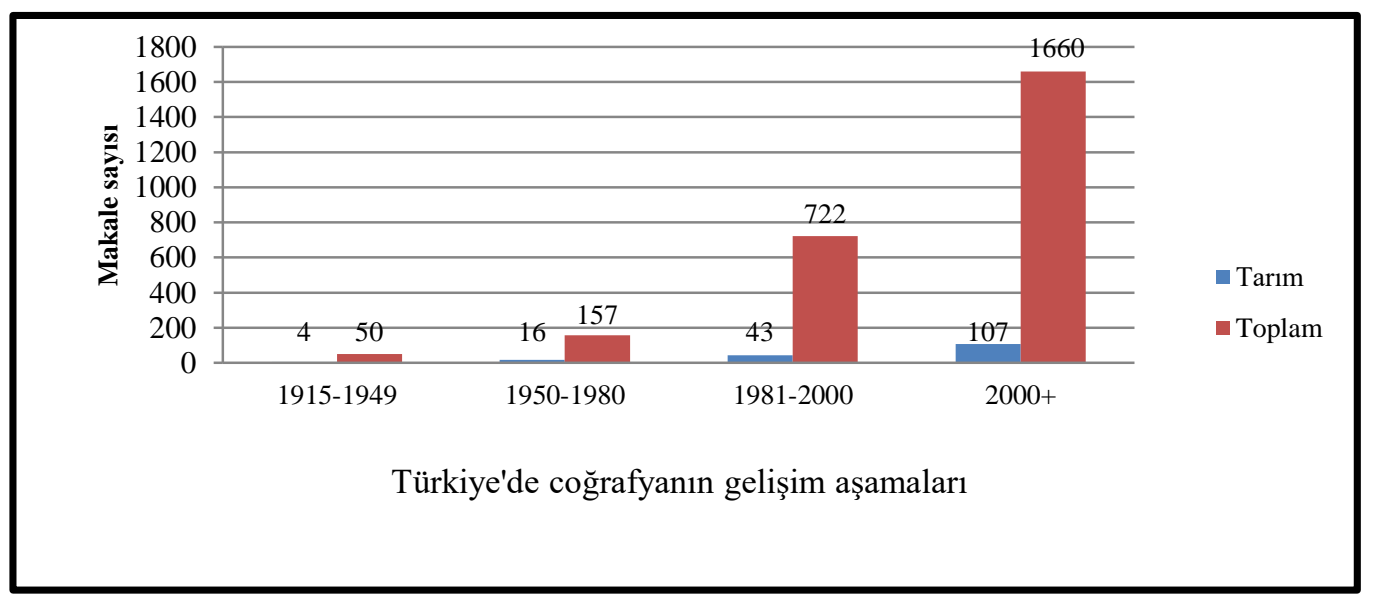

Şekil 1. Türkiye'de dönemlere göre yapılan coğrafya ve tarım coğrafyası makale sayıları

Çizelge 3. Türkiye'de tarım coğrafyasında başlıca çalışma konuları

\begin{tabular}{lllll}
\hline \multirow{2}{*}{ Konular } & \multicolumn{4}{c}{ Dönemler } \\
\cline { 2 - 5 } & $1915-1949$ & $1950-1980$ & $1981-2000$ & $2001+$ \\
\hline Tarımsal üretim & 2 & 6 & 19 & 47 \\
\hline Hayvancılık & 1 & 3 & 5 & 14 \\
\hline Tarımsal yapı ve arazi kullanımı & & & 9 & 24 \\
\hline Amaç dişı arazi kullanımı & & 2 & 2 \\
\hline Seracılık & & 2 & 6 \\
\hline Kursal kalkınma & 1 & & 5 \\
\hline AB uyum & 4 & 7 & 6 & 2 \\
\hline Diğer & 4 & 16 & 43 & 107 \\
\hline Toplam & & & & \\
\hline
\end{tabular}

1981-2000 arasında tarım coğrafyası ile ilgili makale sayısı artmış ve 43 adet makale yayınlanmıştır (Çizelge 2, Grafik 1). İşlenen konularda çeşitliliğin bu dönemde arttığı görülmektedir (Çizelge 3). Çeşitlilik artışının başlangıç yılları olarak nitelenebilecek bu dönemde tarımsal üretim en önemli konudur (19). Tarımsal üretim ile ilgili konular daha çok ülke düzeyinde ve yerel olarak 
yapılmıştır. Dünya ölçüsünde pirinç tarımının makale düzeyinde incelenmesi dönemin başka bir özelliğidir (Gözenç, 1985). Tarımsal yapı ve üretim, amaç dışı arazi kullanımı ve seracılık eklenen başlıca konulardır. Seracılık ile ilgili bir makale yabancı bilim adamı (Struck, 1986) tarafından yayınlanmıştır. Bu durum Türkiye Coğrafyasında ender görülen bir özelliktir. Çalışmanın konusu da tarımsal yeniliğin (seracılık) güney Akdeniz'de yayılması ile ilgilidir. Göney (1986) Sicak Bölgelerde Ziraat Hayatı adlı eseri yazmıştır. Bu dönemin başka bir özelliği, Ziraat Coğrafyası (Doğanay, 1987) başlıklı ilk kitabın yayınlanmasıdır. Dönemde Tümertekin"in $(1984,1997)$ Ekonomik Coğrafya adlı eserinin yeni baskıları yayınlanmıştır. Bu eserin önemli bir bölümünü de tarımsal faaliyetler oluşturmaktadır.

2001 sonrasında Türkiye'de yayınlanan tarım coğrafyası ile ilgili makale sayısı en yüksek seviyeye (107 adet) çıkmıştır (Çizelge 2). Çeşitliliğin zirve yıllarında sekiz adet konu ele alınmıştır. $\mathrm{Bu}$ artış yeni coğrafya bölümlerinin açılması dolayısıyla akademisyen sayısının artışı ile ilgilidir. Kırsal kalkınma (5 adet) ve Avrupa Birliğine uyum süreci (2 adet) ile ilgili çalışmalar ilk kez bu dönemde kaleme alınmıştır. Kırsal kalkınma, Türkiye'de kırsal kalkınma konusu ve Avrupa Birliğine uyum süreci Bakırcı tarafindan makale $(2006,2009)$ ve kitap düzeyinde ele alınırken (2007), Akova (2014), AB tarımsal uyum sürecini makale düzeyinde çalışmıştır. Hayvancılık konusu Koday (2005) tarafından işlenmektedir. Oysa adı geçen bu dönemlerde tarımın Türk ekonomisindeki payında azalmalar görülmeye başlamıştır. Devlet tarımdan uzaklaşmakta veya Keyder ve Yenal'in ifadesiyle "Bildiğimiz Tarımın Sonu, (Küresel, İktidar ve Köylülük) gelmekte" (Keyder ve Yenal 2013), tarım ve kırsallıkta dönüşüm (Günaydın, 2010, Tekeli, 2016) ve küreselleşme ve gida krizi (Aysu 2008, Aysu 2015) yaşanmaktadır. Bulut (2006) ve Doğanay (2007), yıllarında sırasıyla Genel Tarım Bilgileri ve Tarımın Coğrafi Esasları (Ziraat Coğrafyası) ve Ziraat Coğrafyası adlı eserleri yayınlanmıştır. Doğanay ve Coşkun 2012 yılında Tarım Coğrafyası adlı eserin 2. baskısını yayınlamışlardır. Durmuş ve Yiğit 2014 yılında Türkiye'nin tarım bölgeleri ve yöreleri başlıklı bir çalışma yapmışlardır. 2016 yılında Gıda Coğrafyası başlığı ile Güney Aktaş tarafından edit edilen başka bir kitap Anadolu Üniversitesi tarafından yayınlanmıştır. Kitap, turizm fakültesi öğrencileri için yazılmıştır. Öğrencilerin gıda maddelerinin coğrafi dağılışının nedenlerini ve bu maddelerin yemek kültürünü nasıl etkilediğini anlamaları hedeflenmektedir. Göney ve Sertkaya Doğan'ın (2018) Sıcak Bölgelerde Ziraat Hayatı adlı eserinin ikinci baskısı yapılmıştır. Doğan ve Sertkaya Doğan'ın edit ettikleri Beşeri ve Ekonomik Coğrafya (2018) kitabında tarım faaliyetlerine de yer verilmektedir.

\section{Tartışma ve Sonuç}

Tarım ekonomik faaliyetlerin en eski olanıdır. Fiziki ve beşeri koşullarda insanın kontrolünde yapılan bir faaliyet olan tarım, coğrafyanın geleneksel konusudur. Tarımsal faaliyet yoluyla değiş̧en mekânı inceleyen tarım coğrafyasında zaman içinde farklı konular ve yaklaşımlar kullanılmıştır. Bu çalışmada tarım coğrafyasının doğası ve gelişimi araştırma soruları esas alınarak dünya ve Türkiye ölçeğinde ortaya konulmaktadır. Türk Tarım coğrafyasının hangi yönde gelişmesi gerektiği ile ilgili önerilere yer verilmektedir. 
Başlangıçtan günümüze Türk Tarım Coğrafyasında çalışılan konularda çeşitliliğin arttığı görülmektedir. Başlangıç yılları (1915-1949), sınırlı gelişim yılları (1950-1980), tarımsal çeşitliliğin başlangıç yılları (1981-2000) ve tarımsal çeşitliliğin zirve yılları (2001+) Türkiye Tarım Coğrafyasının geçirdiği başlıca evrelerdir. Söz konusu bu dönemlerde çalışılan konular daha çok tarımsal ürünler üzerine olmuştur. $\mathrm{Bu}$ çalışmalarda ülke bazında tarımsal ürünlerin fiziki istekleri ve dağılışları verilmektedir. Tarımsal yap1 ve arazi kullanımı ikinci önemli konu olmuştur. Hayvancılık üçüncü önemli konu başlı̆̆ıdır. Tarımsal ürünü esas alan tematik ve bölgesel yaklaşım dışında yaklaşımlar kullanılmamıştır. Değişen ekonomik şartlara yönelik çalışma sayısı azdır veya yok denecek kadardır. Zamansal olarak tarımsal şartlarda yaşanan konusal değişimlere tepkilere geç cevap verilmiştir. Oysa daha önce ifade edildiği gibi coğrafya 1970'li yıllardan itibaren çoklu bakış açısıyla ele alınır olmuştur. Ekonomik yaklaşım, davranışsal yaklaşım ve radikal yaklaşım gibi yaklaşımlar söz konusudur. Günümüzde dünya hızla değişmekte ve küreselleşme yaşanmaktadır. Bu durum tarım coğrafyasında ele alınan konularda değişikliklere neden olmuştur.

Tarım coğrafyası konuları yeniden gözden geçirilmelidir. Tek bir tarımsal ürene dayalı tarım coğrafyası bakış açısı artık terk edilmiştir. O halde ne yapılmalıdır? Yeniden gözden geçirilecek tarım coğrafyası üç bölüm halinde ele alınabilir. Birinci bölümde tarımı etkileyen fiziki ve beşeri koşullar incelenmelidir. Türkiye'de yayınlanan üç yayında (Bulut 2006, Doğanay ve Coşkun 2012, Tümertekin ve Özgüç 2016) bu konuda ayrıntılı bilgi verilmektedir. Yine tarımın ortaya çıkışı ile ilgili teoriler de verilmelidir (Güran 2009). İlave olarak tarım devrimleri açıklanmalıdır. Bu konuda Carl O. Sauer'un (1952), tarımın ortaya çıkışı ile ilgili fikirlerine de yer verilmelidir.

İkinci bölümde dünya tarım bölgeleri ele alınmalıdır. Bu yapılırken Whittlesey' nin (1936) orjinal eserinden yararlanılmalıdır. Bu bölgelerde yapılan tarımsal faaliyetlere göre bazı tarımsal ürünlerin üretim ve coğrafi dağılışından söz edilmelidir.

Dünya tarımının başlıca sorunları, gıda temini ve açlık konusu üçüncü bölümde ele alınmalıdır. Tarımsal arazinin azalmasının nedenleri ortaya konulmalıdır. AB uyum süreci, tarım ve şehirler, küreselleşme ve tarımsal üretim arasındaki ilişkilerden de söz edilmelidir.

Gelecekte yapılacak çalışmalarda, Fransız ve Alman coğrafyasında tarım coğrafyasının doğası, gelişimi ve kullanılan yaklaşımlar konuya katılmalıdır. 


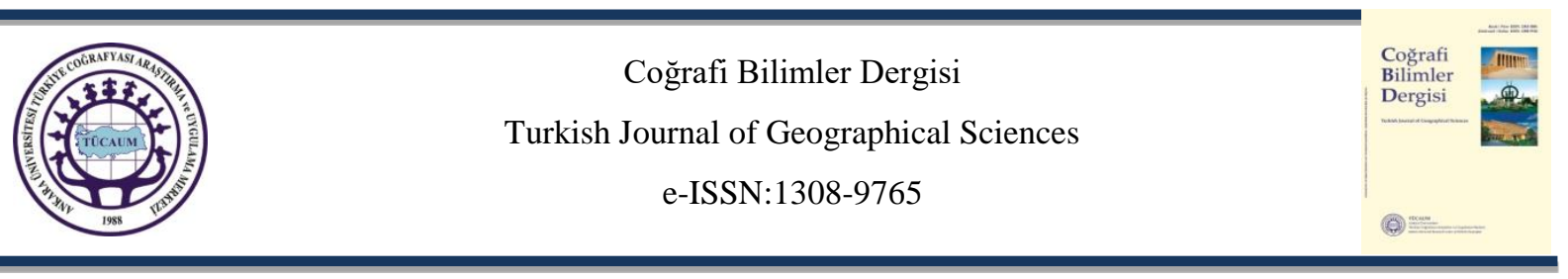

\section{Historical Background Agricultural Geography in the World and Turkey}

Alparslan Aliağaoğlu*a

\section{EXTENDED ABSTRACT}

\section{Introduction}

Agricultural geography is related to spatial aspects of agricultural geographic appearance. Agricultural occupation is shaped by physical and human factors which change according to time and place. Geography has a dynamic structure, leading to emergence and production of different geographical information. The 1950s and 1970s were a turning point for geography and other sciences. Especially in the 1970s, multiple perspectives began to be experienced in the geography. This situation also affected the agricultural geography, but multiple perspectives were not experienced in the same intensity throughout the world. These perspectives in question were not effective in the field of agricultural geography in Turkey.

Revealing the past of a discipline is important in demonstrating its success or failure. A number of studies have been conducted on the history of the geography in Turkey, including those by Akyol (1943a), (1943b), (1943c), Erinç (1973), Erinç (1997), Tümertekin (1971), Tümertekin (1998), Koçman (1999), Kayan (2000), Özgür and Yavan (2013), Gümüşçü and Karakaş Özür (2016). "The Inner World of a Discipline: Conversations on Modern Turkish Geography" (Bekaroğlu and Özdemir, 2014) is another study on this subject. In this work, the nature, development and current status of the subbranches of the geography are given. No studies, however, have been conducted on the background of agricultural geography in Turkey. This study lays the position of agriculture in terms of geography approach in Turkey. The study aims answers the following questions:

a) What is the subject, scope, purpose and research object of agricultural geography today?

b) What is the history and origin of agricultural geography?

c) What are the approaches used in agricultural geography?

d) How has agricultural geography developed in Turkey? Who were the pioneers?

e) Which of the new approaches used in agricultural geography is being used in Turkey?

f) In which direction should agriculture geography develop in Turkey and which issues should it include?

*Corresponding Author: Alpaslan Aliağaoğlu, alpaslan38ster@gmail.com

abalıkesir Üniversitesi, Fen-Edebiyat Fakültesi, Coğrafya Bölümü, Balıkesir, Türkiye, http://orcid.org/0000-0002-6198-3878 
The study is mainly a literature review on agricultural geography based on geography jornal articles published in Turkish geography magazines, books as well as other sources. Existing agricultural geography studies in Turkey were evaluated in terms of positive approach and the development of Anglo-Saxon agricultural geography has been used as a scale for the normative approach. While evaluating the articles and books publised on agricultural geography in Turkey, the historical development stages of Yavan and Özgür (2013) have been used. These stages consist of four phases: Establishment and Institutionalization Phase: The Emergence of Modern Turkish Geography (19151949), Limited Development Phase: Breakthrough and Pause (1950-1980), The Most Difficult Years of Turkish Geography: Dissociation from the Scientific Community (1981-2000) and Revival Phase: New Seekers and Adaptation Efforts (post 2001). In this study, historical periodization has been taken into consideration rather than the stages of development of geography in Turkey

\section{Conceptual Framework}

Agriculture, which has an important position among economic activities, is the production of plants and animal husbandry in different social, economic and physical environments. In the Turkish Dictionary of Science, agriculture is defined as a vital activity, which includes livestock in its broadest sense, based on cultivating soil and obtaining spread products (Turkish Dictionary of Science, 2011: 1101). Agriculture is the first stage of agricultural civilization and is an economic activity or enterprise and a way of life. It is separated from hunting and gathering, Agriculture has many functions as meeting the needs of food and clothing.

The limits of agricultural activities are determined roughly by climate and weather conditions. Within these limits, human intervention in the environment depends on its stage of development. Using science and technology, economic and social institutions and organizations come to the fore in this context. Race, ethnicity, and influence of religion should also be considered. Finally, economic (price and cost) and political conditions also affect agricultural activity (Symons, 1967).

Agricultural geography was influenced by different paradigms that emerged in the history of geography development. In this sense, in the beginning, studies were made with inductive and environmental determinist approach which are parts of systematic and regional perspectives. The commodity-oriented view has been mostly used in the United Kingdom (James and Jones, 1988). The regional perspective was made in Continental Europe. The distribution of some products (tea,cotton,etc.) is described and explained. The studies on this subject are more likely to reveal the agricultural potential of the colonies of Europeans.

Agricultural geography studies in the USA started between 1910 and 1920. Studies were done on land use, soil-slope conditions and detailed mapping of agricultural land in the country. Agricultural activities were handled from the economic point of view in the 1950s and 1960s. In the 1970s and 1980s, there were significant changes in the issues addressed by agricultural geography. Some of new topics taken up include the characteristics of the industrial agricultural system, or globalization in agriculture, agricultural land losses, state intervention in agriculture, and part-time farming. Behavioral approach 
came into prominence in agricultural geography studies in 1970s. The radical model, which has been effective since the 1980s, brings another perspective.

In the early 1990s, attention was directed from the two sides to the concept of farm. First, a wider organization of capital accumulation in the agri-food system needs to be looked at. Secondly, to look at the regulatory structures of this system, focus on the political and policy processes in which national and supranational state institutions support agricultural markets. This expanded efforts to understand agricultural food production and regulation parameters have led to the development of various new concepts such as commodity chains and food regimes (Robinson, 2004).

There exists diversity in agricultural geography studies in Anglo-Saxon countries which have been examined through texts, articles and thesis. The UK stands out first in the field of agricultural land studies. Another feature in general is that a lot of studies have been conducted. As a matter of fact, while the UK was in the foreground with a study on 475 agricultural geography, 255 publications were made in the USA.

\section{Findings and Conclusion}

In the stage of the establishment and institutionalization of Turkey's geography 50 articles were published, only four of which deal with agricultural geography. There were 16 articles published in the agricultural geography between 1950 and 1980, 43 between 1981 and 2000, and reaching the highest level of 107 since 2001.

It is seen that the diversity of the subjects studied in Turkish Agricultural Geography has gradually increased. Initial years (1915-1949), limited development years (1950-1980), the agricultural diversity of the initial years (1981-2000) and agricultural diversity of the peak years (2001+) are the main phases of the agricultural geography in Turkey. The subjects studied during these periods were mainly on agricultural products, agricultural structure and land use and livestock. Those other than thematic and regional approaches based on agricultural products have not been used. The number of studies for changing economic conditions is low or almost nonexistent.

In the peak years of the diversity in the subject matter $(2001+)$, eight issues were addressed, partly due to the increase academics and geography departments in Turkey. There were studies on rural development (5) and European Union (2) for the first, such as the study done by Bakırc1. Akova (2014) published on the EU agricultural adaptation process while animal husbandry has been covered by Koday (2005). However, in these periods, the share of agriculture in the Turkish economy began to decrease. Studies on this subject were mostly written by non-geographers such as Keyder and Yenal (2013), Aysu (2013) among others. Books written in this period on agricultural geography include those of Bulut (2006), Doğanay (2007) and Doğanay and Coşkun (2012). Food geography, agricultural life in the hot zone, Turkey's agricultural regions are the other topics taken up as in the book edited by Güney Aktaş. Doğan and Sertkaya Doğan's book Human and Economic Geography (2018) also includes agricultural activities. 
The perspective of agricultural geography based on a single agricultural product is now abandoned worldwide, so agricultural geography issues in our country should be revised as well. In other words, the individual agricultural products, their agricultural characteristics and their interaction with the natural place have been abandoned. So what should be done? New agricultural geography can be handled in three sections. In the first part, physical and human conditions affecting agriculture should be examined. Again, theories about the emergence of agriculture should be presented (Güran 2009). In addition, agricultural revolutions should be explained. Carl O. Sauer's (1952) ideas about the emergence of agriculture should also be mentioned. In the second part, the world agricultural regions should be discussed. The main problems of world agriculture, food supply and hunger should be discussed in the third chapter. The reasons for the decrease of agricultural land should be put forward. The relationship between the EU harmonization process, agriculture and cities, globalization and agricultural production should also be mentioned.

This study is based on agricultural activities in English-speaking countries, USA, Canada and the UK. Therefore, in future studies, the nature, development and approaches of agricultural geography in French and German geography should also be included.

\section{Referanslar/References}

Akyol, İ. H. (1943a). Son Yarım Asırda Türkiye'de Coğrafya I: Mutlakıyet Devrinde Coğrafya. Türk Coğrafya Dergisi, 1, 3-15.

Akyol, İ. H. (1943b). Son Yarım Asırda Türkiye'de Coğrafya II: Meşrutiyet Devrinde Coğrafya. Türk Coğrafya Dergisi, 2, 121-136.

Akyol, İ. H. (1943c). Son Yarım Asırda Türkiye'de Coğrafya III: Cumhuriyet Devrinde Coğrafya. Türk Coğrafya Dergisi, 3-4, 247- 276.

Anderson, J.R. (1970). A Geography of Agriculture. The Brown Foundations of Geography, Iowa, USA.

Akova, B.S. (2014). Türkiye'de Tarımsal Yapıdaki Değişim Sürecinde Bazı Öngörüler ve Avrupa Birliğine İhracat İmkânları, Güneydoğu Avrupa Araştırmaları Dergisi, 14, .33-56.

Aysu, A. (2015). Glda Krizi, Tarım, Ekoloji, Egemenlik. İstanbul: Metis.

Baker, O.E. (1923). The Agriculture of the Great Plains. Annaals of the Assoc. of American Geographers, 13 (3), 109-167

Bakırcı, M. (2006). Avrupa Birliği Yeni Dönem Kırsal Kalkınma Programı, Türkiye'nin Uyumu ve Yaratacağı Etkiler, Türk Coğrafya Dergisi, 47, 45-74.

Bakırcı, M. (2007). Türkiye'de Kırsal Kalkınma, Nobel Yayınevi: Ankara

Bakırcı, M. (2009). Avrupa Birliği Üyelik Öncesi Destek Fonunun (IPA) Kırsal Kalkınma Bileşeni (IPARD), Türkiye'nin Durumu ve Muhtemel Etkileri, Doğu Coğrafya Dergisi, 21, 53-78.

Bekaroğlu, E., Özdemir, A.R (Ed). (2014). Bir Disiplinin İ̧̧ Dünyası: Modern Türk Coğrafyası Üzerine Söyleşiler. İstanbul: İdil Yayıncılık.

Bengtson, N.A., Van Royen, W. (1956). Fundamentals of Economic Geography. NJ; Prentice-Hall

Bulut, İ. (2006). Genel Tarım Bilgileri ve Tarımın Coğrafi Esasları (Ziraat Coğrafyası), Ankara: Gündüz Eğitim ve Yayınc1lik.

Doğan, S. Ö. (2018). Tarım Coğrafyası. Beşeri ve Ekonomik Coğrafya içinde, M. Doğan ve Ö.S. Doğan (Ed.), Ankara: Pegem Akademi, 199-274.

Doğan, M, Doğan, Ö.S. (Ed).(2018). Beşeri ve Ekonomik Coğrafya. Ankara: Pegem Akademi.

Doğanay, H. (2007). Ziraat Coğrafyası, Erzurum: Aktif Yayınevi. 
Doğanay, H., Coşkun, O. (2012). Tarım Coğrafyası (Güncellenmiş 2. Baskı). Ankara: Pegem Akademi.

Durmuş, E., Yiğit, A. (2014). Türkiye'nin Tarım Yöreleri ve Bölgeleri. Ankara: Nobel.

Emiroğlu, K., Danışoğlu, B., Berberoğlu, B. (2006). Ekonomi Sözlü̆̆̈̈. Ankara: Bilim ve Sanat.

Erinç, S. Tunçdilek, N. (1952). The Agricultural Regions of Turkey, Geographical Review, 42 (2), 179-203.

Erinç, S. (1973). Cumhuriyetin 50. Yılında Türkiye’de Coğrafya, Ankara: Başbakanlık Kültür Müsteşarlığı Cumhuriyetin 50. Yı1dönümü Yayınları.

Erinç, S. (1997). Coğrafya. Cumhuriyet Döneminde Türkiye’de Bilim: Sosyal Bilimler I içinde, Ankara: TÜBA Yayınları, $51-56$

Göney, S. (1979). Türkiye Ziraatinin Coğrafi Esasları 1. İstanbul: İstanbul Üni. Yayınları No. 2600.

Göney, S. (1986). Sicak Bölgelerde Ziraat Hayatı. Ziraat Coğrafyası, Cilt IV, İstanbul: Coğrafya Enstitüsü Yayınları.

Göney, S., Doğan, Sertkaya. Ö. (2018). Sicak Bölgelerde Ziraat Hayatı (2. Basım). Nobel Yayınları: İstanbul.

Gözenç, S., (1985). Japonya ve Güneydoğu Asya'da Pirinç Tarımı, İstanbul Üniv. Deniz Bilimleri ve Coğrafya Enstitüsü Bülten,2 (2)

Gregor, H.F. (1970). Geography of Agriculture: Themas in Research, N.J: Prentice-Hall Inc., Englewood Cliffs.

Grigg, D. (1969). The Agricultural Regions of the World: Review and Reflections, Economic Geography, 45 (2), 95-132

Grigg, D. (1974). The Agriculturl Systems of the World. London: Cambridge University Press.

Grigg, D. (1995). An Itroduction to Agricultural Geography (Second Edition). New York: Routledge.

Gümüşçü, O. Karakaş Özür, N. (2016). Türkiye'de Modern Coğrafyanın Kuruluşu ve Örgütlenmesi (1915-1945), Atatürk Araştırma Merkezi Dergisi (ATAM), Cilt XXXII, 93, Bahar, 105-147.

Günay Aktaş, S (Ed.). (2016). Gıda Coğrafyası. Eskişehir: Anadolu Üniversitesi Yayınları.

Günaydın, G. (2010). Tarım ve Kırsallıkta Dönüşüm, Politika Transfer Süreci/AB ve Türkiye. Ankara: Tan Kitabevi Yayınları.

Güran, T. (2009). İktisat Tarihi, İstanbul: Der Yayınları

Ilbery, B. (1983). Goals and Values of Hop Farmers, Transactions of the Institute of British Geographers, 8 (3), 329- 341

Ilbery, B. (1985). Agricultural Geography, A Social and Economic Analysis, Oxford: Oxford Üniversity Press.

İzbırak, R. (1986). Coğrafi Terimler Sözlüğ̈̈. İstanbul: Milli Eğitim Basımevi.

James, P.E., Jones, C.F. (1988). American Geography: Inventory and Prospect. Jaipur:Rawat Publication.

Jones, C., Darkenwald, G. (1965). Economic Geography, New York.

Kayan, İ. (2000). Türkiye Üniversitelerinde Coğrafya Eğitimi: Amaç, Yeni Hedefler, Sorunlar ve Öneriler, Ege Coğrafya Dergisi, 11, 7-22.

Keyder, Ç., Yenal, Z. (2013). Bildiğimiz Tarımın Sonu, Küresel, İktidar ve Köylülük, İletişm: İstanbul.

Klages, K.H.W. (1942). Ecological Crop Geography, USA: The Macmillan Company.

Koçman, A. (1999). Cumhuriyet Döneminde Yükseköğretim Kurumlarında Coğrafya Eğitimi ve Sorunları, Ege Coğrafya Dergisi, 10, 1-14.

Koday, S. (2005). Doğu Anadolu Bölgesinde Hayvancılık, Erzurum: Atatürk Üniversitesi Yayınları.

Marsden T, Munton R, Ward N., Whatmore S. (1996). Agricultural Geography and the Political Approach, Economic Geography, Vol. 72 (4),361-375.

Morgan, W.B., Munton, R.J.C. (1971). Agricultural Geography. London: Methuen \& Co. Ltd.

Özçağlar, A. (2003). Coğrafyaya Giriş, Sistematik, Kavramlar, Yöntemler. Ankara: Hilmi Usta Matbaacılık.

Özgür, E.M., Yavan, N. (2013). Türk Coğrafyacılarıının İç Hesaplaşması: Neden Başaramadık? Nasıl Başarabiliriz? Beşeri Coğrafya Dergisi 1(1), 14-38. 
Robinson, R. (2004). Geography of Agriculture, Globalisation, Restructuring, and Sustainability, Pierson Printice Hall.

Rumney, T.A. (2005). The Study of Agricultural Geography, A Scholarly Guide and Bibliography. Oxford: The Scarecrow Press, Inc.

Rüstow, A. (1939). İktisadi Coğrafya (1. Cilt), İstanbul.

Tekeli, İ. (2016). Dünya'da ve Türkiye'de Kır-Kent Karşıtlığı Yok Olurken Yerleşmeler İçin Temsil Sorunları, İdeal Kent: Ankara.

Thoman, R. S. (1962). Geography of Economic Activity, New York: McGraw-Hill,

Tümertekin, E. (1957). Kurak Bölgelerde Ziraat Hayatı, İstanbul: İ.Ü. İktisat Fakültesi Yayın1.

Tümertekin, E. (1961). Beşeri ve İktisadi Coğrafya Dersleri, İstanbul.

Tümertekin, E. (1964). Changing Picture of Female participation in Turkish Agriculture, The Professional Geographer, 13 (2), 39-45.

Tümertekin, E. (1971). Türkiye’de Beşeri Coğrafyanın Gelişmesi. Türkiye: Coğrafi ve Sosyal Araştırmalar içinde, E. Tümertekin, F. Mansur P. Benedict (Eds), İstanbul: İstanbul Üniversitesi Edebiyat Fakültesi Yayını, 1-16

Tümertekin E. (1972). İktisadi Coğrafya, İstanbul: İstanbul Üniversitesi Yayınları: 1703, İstanbul.

Tümertekin, E. (1984). Ekonomik Coğrafya, İstanbul: İstanbul Üniversitesi Fen-Edebiyat Fakültesi Yayınları No. 2926.

Tümertekin, E., Özgüç, N. (1997). Ekonomik Coğrafya, Küreselleşme ve Kalkınma, İstanbul: Çantay Kitabevi.

Tümertekin, E. (1998). Beşeri Coğrafya, Cumhuriyet Döneminde Türkiye'de Bilim, Sosyal Bilimler II içinde (187-215), Ankara: Türkiye Bilimler Akademisi.

Tümertekin, E, Özgüç, N. (2016). Ekonomik Coğrafya, Küreselleşme ve Kalkınma. İstanbul: Çantay Kitabevi.

Türkçe Bilim Terimleri Sözlüğü, Sosyal Bilimler. (2011). TÜBA, Ankara: Türkiye Bilimler Akademisi.

Türkoğlu, A. (1958). İktisadi Coğrafya Dersleri 1. Kitap Gıda Maddeleri, İstanbul: İstanbul Üniv. Yayınları No. 2563.

Sauer, C.O. (1952). Agricultural Origins and Dispersals, New York: George Grady Press.

Singh, J., Dhillon, S.S. (2004). Agricultural Geography. New Delhi: Tata McGraw-Hill Publishing Company Limited.

Struck, E. (1986). Türkiye'nin Güney Kıyı Bölgesinde Tarımsal Bir Yeniliğin Yaygınlaşması: Seracılık, $\dot{I} . \ddot{U}$. Deniz Bilimleri ve Coğrafya Enstitüsü, Bülten, 2 (3), 79-90.

Symons, L. (1967). Agricultural Geography, New York: Praeger Publishers.

Visher, S.S., Hu, C.Y. (1950). Oliver Edwin Baker, 1883-1949, Annals of the Association of American Geographers, 40 (4), 328-334

Whittlesey, D. (1936). Major Agricultural Regions of the Earth, Annals of the Association of American Geographers 26, $199-240$ 